\title{
O debuxo como método para mellorar a comunicación nunha nena con TEA
}

\section{Drawing as a method to improve communication in a female child suffering from DAE}

\author{
Berta Fraga, Marta Meizoso, Beatriz López \\ Asociación DISMACOR, Culleredo. A Coruña. España.
}

\begin{abstract}
Resumen
O autismo é un trastorno do neurodesenvolvemento que supón afectacións a nivel psicolóxico e condutual das persoas que o presentan. En todas as persoas diagnosticadas con algún trastorno do espectro autista son frecuentes as dificultades de comunicación. Esta dificultade provócalles un illamento da sociedade e das súas familias e adoita supoñer un malestar considerable para eles mesmos e aos que lles rodean. No presente traballo mostramos unha proposta de intervención para mellorar as dificultades de comunicación dunha nena de oito anos diagnosticada con TEA e que presenta unha linguaxe pouco emotiva e carente de sentimentos.

Palabras clave: autismo, intervención en contorna natural, manifestación de emocións.
\end{abstract}

\section{Abstract}

Autism is a neuro-developmental disorder involving psychological and behavioural affectations in individuals who suffer from it. In every individual diagnosed with a disorder of autism spectrum communicative difficulties are observed very frequently, thus preventing them from being well adapted to the world they are living in. That difficulty causes problems in their social and family circles and a substantial impact for themselves and those around them. In this assignment we are introducing an intervention proposal in order to improve communicative difficulties in an eight-year-old female child diagnosed with DAE showing less emotive, without feeling expression language.

Keywords autism, natural surroundings intervention, expressing emotions

\section{Introdución}

O autismo é un trastorno do neurodesenvolvemento que ten a súa orixe nas idades temperás, e que se concreta na presenza de alteracións que afectan, primordialmente, a tres aspectos (Idiazábal-Áletxa e Boque-Hermida, 2007): déficits na interacción social, dificultades no desenvolvemento lingüístico e patróns de conduta e intereses moi restrinxidos (DSM V).

Patróns de conduta, intereses ou actividades restritivas e repetitivas.

É frecuente nos nenos con autismo que presenten movementos ou fala estereotipada e repetitiva (saltos, xirar obxectos, alinealos, ecolalias ...) que soen emparellarse aos momentos de maior excitación emocional do neno.

Outro aspecto do que se derivan constantes problemas para adaptarse ao mundo que lles rodea e a súa inflexibilidade que se manifesta na imposibilidade de aceptar cambios nas súas rutinas, presenza de rituais e a existencia de intereses moi restrinxidos.
Un aspecto moi importante dentro deste bloque sintomatolóxico é a hipersensibilidade sensorial que soe manifestarse na presenza dun elevado nivel de tolerancia á dor, hiperreactividade a sons e texturas, fixación por analizar os estímulos dun xeito peculiar (lambelos, ulilos ...) e un interese agudizado por determinados patróns estimulares (como poden ser luces ou obxectos en movemento).

Déficits nas relación sociais e na interacción comunicativa con outras persoas

Os nenos con autismo manifestan dificultades no mantemento de contacto ocular e as aproximacións ás demais persoas, problemas para comprender as emocións dos demais e empregalas para poder dar resposta ás mesmas, déficits para participar en conversas e utilizar as fórmulas de relación axeitadas para poder manter unhas relacións correctas cos que lles rodean. Estas dificultades tamén se palpan en problemas para o bo desenvolvemento da comunicación non verbal (linguaxe corporal, utilización de xestos ...).

Estas limitacións provocan nos nenos, normalmente, problemas para relacionarse cos seus iguais ao non ser quen de comprender ditas relacións e axustar o seu comportamento aos continuos cambios que ocorren nas mesmas.

\section{Afectación no desenvolvemento lingüístico e comunicativo}

O desenvolvemento dos nenos con autismo soe proseguir uns patróns normais ata os 18 meses (Buceta, 2011), momento no cal tanto os familiares como os profesionais refiren o comezo da perda de habilidades adquiridas e a aparición de comportamentos estraños, problemas que van restrinxindo a adaptación do pequeno ao mundo que lle rodea.

Os déficits e o funcionamento dos nenos con autismo varía considerablemente dun individuo a outro, pero un aspecto que soen ter en común todos eles son as dificultades no inicio da fala, os nenos con autismo presentan un retraso na aparición da linguaxe verbal (Rodríguez-Barrionuevo e Rodríguez-Vives, 2002), aínda que moitos deles chegan a acadar un nivel de competencias verbais que lles permiten comunicarse sen problemas (Wodka, Mathy e Kalb, 2013).

A linguaxe dos nenos autistas presenta unhas características propias: adoitan manifestar múltiples ecolalias formadas por frases perfectamente formadas que son aprendidas literalmente de anuncios ou frases feitas e que non soen ter unha base funcional no seu uso. Doutra banda, os nenos non son quen de utilizar os xestos ou a expresión facial para suplir os déficits lingüísticos que manifestan, normalmente o xesto non 
está emparellado co acto comunicativo e é normal que o utilicen como fin para dirixir ao adulto cara os seus desexos. Neste mesmo sentido, atópanse problemas no correcto uso dos pronomes persoais e na utilización dos mesmos para describirse a si mesmos; así, os nenos con autismo soen falar en terceira persoa e referirse a súa persoa polo seu nome de pila. Investigacións recentes emparellan esta dificultade cos problemas cognitivo sociais propios do autismo (Artigas, 1999).

En todos os casos de autismo atópanse alteracións pragmáticas e comunicativas, que se materializan en déficits para a correcta adquisición dos compoñentes estruturais ou gramaticais, problemas no desenvolvemento da comunicación intencional e conversacional e alteracións na comprensión referencial que permite comprender o que sinte e que re dicir a outra persoa (Sixto e Belinchón, 1997). Estas dificultades semántico-pragmáticas derívanse dos problemas de comprensión social que lles dificulta interpretar o pensamento do seu interlocutor e que lles leva a xulgar e definir o mundo sempre polos seus intereses e gustos.

Estes déficits na comunicación social pódense explicar de acordo a varias teorías que se postularon para explicar o funcionamento das persoas con autismo: Teoría da Mente, segundo a cal as persoas con autismo manifestan problemas para atribuír os estados mentais para explicar tanto o propio comportamento como o dos que lle rodean (Tirapu-Ustárroz, Pérez-Sayes, ErekatxoBilbao e Pelegrín-Valero, 2007). Teoría da Coherencia Central, que explica a incapacidade dos autistas para procesar a información que se lles mostra atendendo soamente aos detalles e non sendo quen de contextualizala nun referente máis amplo (Frith, 2003) e a Teoría Emocional que considera que existe un déficit intersubxectivo nas persoas con autismo (Buceta, 2011) que lles dificulta a capacidade innata de relacionarse con outros e, polo tanto, de aprender a identificar os seus estados emocionais.

Máis recentemente, outras teorías relacionan os problemas de comunicación social con déficits na cognición social, que se deberían a problemas para coordinar a atención a un interlocutor e a un contexto. A esta nova definición coñécese baixo o nome de "atención conxunta" e atópanse evidencias empíricas de que os nenos comezan a realizar actividades para poder manter una comunicación eficaz xa dende os seis meses de vida (dirixir a mirada ao interlocutor, observar ...); precisamente, no caso dos nenos con autismo atopáronse patróns diferentes de desenvolvemento deste tipo de condutas xa dende os primeiros días. Neste sentido, os autistas presentan problemas para intercambiar emocións cos demais e para comprender ditas emocións (Alessandri, Mundy e Tuchman, 2005).

En canto aos relato neurolóxicos, diferentes investigacións atopan afectacións na amígdala e en rexións relacionadas como posible explicación destas dificultades para a comunicación social nas persoas con autismo (Tuchman, 2001). Así mesmo, atópanse déficits no funcionamento dos lóbulos frontais que controlan as funcións executivas que se encargan xe planificar e controlar as accións e o pensamento, memoria de traballo, control inhibitorio e resolución de problemas que implican a representación mental, problemas de interacción social, comunicativos e afectivos (Comin, 2013).

\section{Método}

\section{Participantes}

O protagonista da proposta de intervención é unha nena de 8 anos diagnosticada cun Trastorno do Espectro Autista dende o ano e medio. Comorbidamente se lle diagnosticou un cadro de Trastorno Obsesivo Compulsivo.

A nena cursa actualmente terceiro de educación primaria nun centro ordinario con pequenas adaptacións que non implican a modificación significativa do currículo. A súa vez recibe unha hora semanal de atención psicolóxica a domicilio pola nosa asociación.

\section{Obxectivos}

O obxectivo principal desta proposta de intervención é dotar a nena dun método eficaz para poder comunicar os seus sentimentos e comprender o xeito de comportarse dos demais, elaborando respostas axeitadas que lle permitan adaptarse a súa contorna:

- Aumentar a comprensión de frases feitas, dobres sentidos e chistes.

- Mellorar a identificación e expresión de sentimentos.

- Mellorar a comprensión de situacións sociais.

\section{Procedemento}

O temperá diagnóstico da nena permitiu que reciba intervención dende moi pequena e presenta un moi bo funcionamento. O comezo da linguaxe verbal sitúase en torno aos catro anos, momento no que a nena comeza a emitir pequenas palabras soltas. Pouco a pouco a nena vai adquirindo o concepto de frase e, actualmente, a nena presenta un desenvolvemento lingüístico que se corresponde co esperado para a súa idade.

A pesar de que a nena é quen de relatar historias e experiencias verbalmente sen ningún problema; atópanse problemas para a referencia emocional dos estados que lle suscitan ditas situacións. Nótese que a nena é quen de describir obxectivamente o que lle sucedeu pero nunca fai referencia aos seus sentimentos nin aos dos que lle rodean.

$\mathrm{O}$ feito de que a pequena recibise intervención con apoios visuais dende unha idade tan temperá implica que a nena o reclame como medio para poder apoiar os mensaxes verbais que se lles mostran. Concretamente, precisamos utilizar estes apoios visuais para complementar todas as nosas explicacións (aínda que a nena comprender perfectamente os mensaxes verbais) para conseguir que os asimile a os poida xeralizar na súa vida cotiá, entendendo que a capacidade visual é o aspectos sensorial que ten a maior competencia nos nenos con autismo.

Partindo da base de que o propio terapeuta funciona como un modelo para ir aprendendo respostas axeitadas, a nena vaia adquirindo a capacidade de mostrar simbolicamente as experiencias vividas. O primeiro paso correspóndese coa identificación dos sentimentos 
mediante reforzos visuais para, posteriormente, ila instruíndo na capacidade de mostrar simbolicamente os mesmos. Co tempo durante a realización das sesións comezouse a notar que, na realización dos debuxos, a nena comezaba a mostrar toda a carga emocional que non era quen de plasmar mediante a verbalización.

Utilízanse estas manifestacións para que a nena as utilice como apoio para poder ir mostrando os seus propios sentimentos e a vivencia das situacións; pois, aínda sen ser capaz de manifestalo, moitas veces aparecían atribucións emocionais incorrectas sobre os pensamentos e sentimentos dos demais.

\section{Resultados e conclusións}

A utilización dos apoios visuais como referente para complementar as explicacións verbais nos nenos con autismo axuda a organizar o patrón estimular que lles presentamos e constitúe unha base sólida para que os nenos poidan ir asimilando aqueles aspectos que desexamos mostrarlles. A continuación móstrase unha táboa onde se recollen os avances conseguidos trala implantación deste modelo de intervención.

\begin{tabular}{|c|c|}
\hline $\begin{array}{l}\text { Funcionamento } \\
\text { anterior á implantación } \\
\text { da intervención }\end{array}$ & Funcionamento actual \\
\hline $\begin{array}{l}\text { A nena non era capaz de } \\
\text { recoñecer os seus } \\
\text { sentimentos. } \\
\text { A nena non era quen de } \\
\text { recoñecer os sentimentos } \\
\text { dos demais. }\end{array}$ & $\begin{array}{l}\text { Actualmente a nena é } \\
\text { quen de recoñecer e } \\
\text { clasificar os diferentes } \\
\text { sentimentos tanto en si } \\
\text { mesma como nos } \\
\text { demais. En consonancia } \\
\text { pode analizalos e atopar } \\
\text { os consecuentes e os } \\
\text { antecedentes dos } \\
\text { mesmos. }\end{array}$ \\
\hline $\begin{array}{l}\text { A nena tendía a } \\
\text { responder de xeito } \\
\text { inadecuado ás situacións } \\
\text { sociais. }\end{array}$ & $\begin{array}{l}\text { Nestes momentos a nena } \\
\text { pode identificar todo un } \\
\text { amplo repertorio de } \\
\text { respostas sociais e ensaia } \\
\text { as posibles respostas. } \\
\text { Obsérvase, neste sentido, } \\
\text { unha mellor empatía cos } \\
\text { que lle rodean, } \\
\text { preocupándose de mutuo } \\
\text { propio polos sentimentos } \\
\text { dos que lle rodean. }\end{array}$ \\
\hline $\begin{array}{l}\text { A nena non era quen de } \\
\text { verbalizar os seus } \\
\text { sentimentos e desexos e } \\
\text { tendía a montar rabietas } \\
\text { cando as súas } \\
\text { expectativas non eran } \\
\text { satisfeitas. }\end{array}$ & $\begin{array}{l}\text { Agora a nena comeza a } \\
\text { verbalizar os seus } \\
\text { sentimentos sen } \\
\text { necesidade de que outra } \\
\text { persoa lle inste a facelo, } \\
\text { ademais, é quen de } \\
\text { verbalizar aquelas } \\
\text { condutas que debería } \\
\text { levar a cabo para poder } \\
\text { controlar os seus } \\
\text { impulsos. }\end{array}$ \\
\hline
\end{tabular}

Táboa 1.: Progreso conseguido trala implantación da intervención.
A utilización do debuxo como método para que a nena poida manifestar os seus propios sentimentos e os dos demais mostra mellores resultados no traballo coa Teoría da Mente, de feito que ela mesma é quen de identificar diferentes emocións (cada vez máis variadas e complexas) e atribuílas aos demais.

Todas estas capacidades redundan nunha mellor capacidade para comprender o mundo que lle rodea e, sobre todo, para ir modulando as súas respostas de cara a atender os sentimentos dos demais. Mellórase, así mesmo, a empatía da pequena e a súa relación cos que lle rodean, sendo quen de mostrar afecto, desagrado, desgusto ... sempre cun patrón de respostas adaptativo.

\section{Referencias}

Alessandri, M., Mundy, P. e Tuchman, R.F. (2005). Déficit Social en el Autismo: un Enfoque en la Atención Conjunta. Neurol, 40 (1).

Artigas, J. (1999). El Lenguaje en los Trastornos Autistas. Revista de Neurología, 28 (2).

Buceta, M.J. (2011). Manual de Atención Temprana. Madrid: Editorial Síntesis S.A.

Comin, D. (2013). El Déficit en la Función Ejectuvia y su Impacto en el Autismo [Mensaje en un blog]. Recuperado de http://autismodiario.org/2013/12/20/eldeficit-en-la-funcion-ejecutiva-y-su-impacto-en-elautismo/

DSM V

Idiazábal-Aletxa e Boque-Hermida, E. (2007). Procesamiento Cognitivo en los Trastornos del Espectro Autista. Neurol 44 (2).

Frith, U. (2003). Autism: Explaining the Enigma. Oxford: Blackwell Publishing.

Rodríguez-Barrionuevo e Rodríguez-Vives, M.A. (2002). Diagnóstico Clínico del Autismo. Neurol, 34 (1).

Sixto, J. e Belinchón, M. (1997). Ineficacia en la Comunicación Referencial de Personas con Autismo y otros Trastornos relacionados: un Estudio Empírico. Anuario de Psicología, 75.

Tirapu-Ustárroz, J., Pérez-Sayes, G., Erekatxo-Bilbao, M. e Pelegrín-Valero, C. (2007). ¿Qué es la Teoría de la Mente? Neurol, 44 (8).

Tuchman, R.F. (2001). Como Construir un Cerebro Social: lo que nos Enseña el Autismo. Revista de Neurología, 1.

Wodka, E.L., Mathy, P. e Kalb, L. (2013). Predictors of Phrase and Fluent Speech in Children with Autism and Severe Language Delay. Pediatrics, 4. 